\title{
Low Adherence to Mediterranean Diet in Portugal: Pregnant Women Nutrition in Portugal and its Repercussions
}

\author{
Baixa Adesão à Dieta Mediterrânica em Portugal: \\ Nutrição das Grávidas em Portugal e suas Repercussões
}

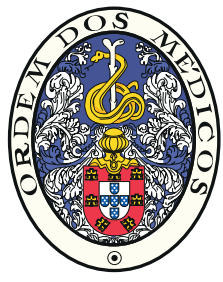

\author{
Luís PEREIRA-DA-SILVA $\square^{1,2}$, Elisabete PINTO3,4 \\ Acta Med Port 2016 Oct;29(10):658-666 - http://dx.doi.org/10.20344/amp.7344
}

\section{ABSTRACT}

Introduction: Portuguese population is drifting away from the Mediterranean diet-like pattern. In this context, the current nutritional status of women of childbearing age and of pregnant Portuguese women and their growing fetuses is critically reviewed.

Material and Methods: A narrative critical review was performed on recent published high quality studies assessing diet and nutritional status of women of childbearing age and pregnant women and its influence on the nutritional status of their offspring.

Results: Data from five multinational ecological studies that included Portugal, two national official surveys on food availability, seven national studies on the diet and nutritional status of women of childbearing age and pregnant women, and five national studies on the effect of nutritional maternal factors on their growing fetuses were selected and analyzed. The prevalence of overweight/obesity has dramatically increased in Portuguese women of childbearing age and pregnant women, associated with the described trend of low adherence to Mediterranean diet. Variations in energy and macronutrients intakes during pregnancy seem to have no significantly impact on the nutritional status of growing fetuses. On contrary, pre-pregnancy overweight/obesity has been associated with increased offspring adiposity at birth, and an excessive gestational weight gain may be associated with offspring's overweight status in childhood. Factors potentially contributing to low adherence to the Mediterranean diet, deserving further investigation, include European Union agriculture policies that have implemented the production of non-Mediterranean food groups at low cost, and insufficient financial capacity to afford foods of quality reported by Portuguese population.

Conclusion: Retrieving traditional Mediterranean dietary habits should be incorporated into strategies for prevention and treatment of overweight/obesity in Portugal, especially in women of childbearing age.

Keywords: Diet, Mediterranean; Patient Compliance; Portugal; Pregnancy; Pregnant Women.

\section{RESUMO}

Introdução: Tem havido baixa adesão ao padrão da dieta mediterrânica na população portuguesa. Nesta perspectiva, procedemos à revisão crítica do estado de nutrição das mulheres em idade fértil, grávidas e recém-nascidos, em Portugal.

Material e Métodos: Realizámos uma revisão narrativa crítica de estudos recentes com qualidade e inquéritos nacionais oficiais, que tivessem avaliado a dieta e estado de nutrição de mulheres em idade fértil e de grávidas portuguesas e sua influência no estado de nutrição dos respetivos fetos e recém-nascidos.

Resultados: Foram selecionados e analisados cinco estudos ecológicos multinacionais que incluíram Portugal, dois inquéritos oficiais nacionais sobre disponibilidade de alimentos, sete estudos nacionais sobre dieta e estado de nutrição de mulheres em idade fértil e grávidas e cinco estudos nacionais sobre a influência de fatores nutricionais maternos no crescimento dos fetos. A prevalência de excesso de peso/obesidade em mulheres em idade fértil e grávidas aumentou substancialmente associada à diminuição da adesão à dieta mediterrânica. As variações no consumo de energia e macronutrientes na gravidez parecem não ter impacto significativo no estado de nutrição dos fetos. Pelo contrário, o excesso de peso/obesidade pré-concecional associa-se a aumento de adiposidade ao nascer e o excessivo aumento de peso na gravidez associa-se ao excesso ponderal na infância. Os fatores potencialmente relacionados com a baixa adesão à dieta mediterrânica, merecendo futura investigação, incluem políticas agrícolas da União Europeia que promoveram a produção de grupos alimentares não tipicamente mediterrânicos a baixo preço e a pouca capacidade financeira referida pela população portuguesa para aquisição de alimentos de qualidade.

Conclusão: A recuperação dos hábitos dietéticos mediterrânicos tradicionais deve ser incluída em estratégias de prevenção e tratamento do excesso de peso/obesidade em Portugal, especialmente em mulheres em idade fértil.

Palavras-chave: Cooperação do Doente; Dieta Mediterrânica; Gestantes; Gravidez; Portugal.

\section{INTRODUCTION}

The Mediterranean diet does not stand for a homogenous and exclusive model among the 16 countries situated around the Mediterranean Sea. Nevertheless, a Mediterranean diet-like pattern is common in Mediterranean countries, which is based on a set of healthy dietary habits that include high consumption of unprocessed and plant foods, such as grains, nuts, fresh and seasonal fruits, and the use of olive oil as the main source of fat. ${ }^{1,2}$ In addition, Mediterranean diet is characterized by its frugality and moderation, and it also stimulates conviviality during meals. ${ }^{2}$

The populations' vastly changing dietary patterns have more recently led Mediterranean countries into a

1. Woman, Children and Adolescent's Medicine Teaching and Research Area. NOVA Medical School. Universidade NOVA de Lisboa. Lisbon. Portugal.

2. Neonatal Intensive Care Unit. Hospital Dona Estefânia. Centro Hospitalar de Lisboa Central. Lisbon. Portugal.

3. Centro de Biotecnologia e Química Fina. Laboratório Associado. Escola Superior de Biotecnologia. Universidade Católica Portuguesa. Porto. Portugal.

4. Institute of Public Health. University of Porto. Porto. Portugal.

$\triangle$ Autor correspondente: Luis Pereira-da-Silva. I.pereira.silva@chlc.min-saude.pt

Recebido: 29 de dezembro de 2015 - Aceite: 30 de agosto de 2016 | Copyright @ Ordem dos Médicos 2016 
nutrition transition similar to that of many other regions in the world, likely contributing to the increased burden of non-communicable diseases and obesity. ${ }^{3}$ These changes have been fairly rapid, causing imbalance between people, genetic programming, environmental exposures and, consequently, occurrence of disease. ${ }^{3} \mathrm{~A}$ major concern is the early abandonment of Mediterranean dietary patterns established during childhood and adolescence, leading to replacement of traditional dietary habits with those of some USA and northern European diets characterized by greater consumption of red meat, butter and animal fats, added sugars and salty foods. ${ }^{4-7}$

Evidence from observational studies (ecological, cohort, or case-control) supports a protective effect of Mediterranean dietary patterns not only on weight gain, metabolic outcomes, and cardiovascular risk factors, but also probably on asthma, some neurodegenerative diseases and cancers. ${ }^{1,7-9}$ Some of these and other benefits have been linked to very early nutrition and may even trace back to pregnancy. ${ }^{6,10-12}$ The timeframe of the first 1,000 days of life between the first day of gestation and the offspring's second anniversary represents a critical window in which overweight programming takes place and probably the best opportunity to prevent obesity and shape a healthier future. ${ }^{13}$ The spread of the obesity epidemic to many Mediterranean countries warrants urgent action to be taken to retrieve traditional Mediterranean dietary habits and promote healthy lifestyles, including involvement of the scientific community, health care providers, public, and policy-makers. ${ }^{14}$

Portugal is the most western country in South Europe and is geographically not in the Mediterranean basin. However, Mediterranean diet is a settled cultural heritage of Portuguese population, with ancestral influence from the Mediterranean neighbors and specificities from migrants. Other specific factors, such as the own cultural and socioeconomic context, genetic background, and the potentially increased availability of fish due to its wide Atlantic coast have influenced the diet of Portuguese population. It is not known to what extent the influence of Western dietary habits, some active European Union agriculture policies, and financial capacity to afford foods of quality have contributed for drifting away from traditional dietary habits of Portuguese population, especially in women of childbearing age and pregnant women.

This narrative review critically gathers data from recent publications on the adherence of Portuguese women of childbearing age to the Mediterranean-like dietary pattern, the diet and nutritional status of Portuguese pregnant women and its effect on their growing fetuses.

\section{MATERIAL AND METHODS}

\section{Search strategy}

Published national cohort studies, surveys, and crosssectional studies as well as multi-national studies that have included Portugal data, investigating adherence of Portuguese women of childbearing age to the Mediterranean- like dietary pattern, diet and nutritional status of Portuguese pregnant women, and growth of their fetus/neonates were searched. A further refinement selected studies published in the last ten years (from November 2005 to January 2015). References from the extracted articles and reviews were also consulted to complete the data collection. The search strategy had no language restrictions and was based on the electronic databases Medline, Embase, Web of Science, and the Cochrane Library as well as the Portuguese biomedical database Índex das Revistas Médicas Portuguesas (www.indexrmp.com). Official reports from the Statistics Portugal/ Instituto Nacional de Estatística website (www.ine.pt) were also searched. The relevant keywords used were: body composition, fetal nutrition, food availability, gestational weight gain, infant, maternal diet, maternal obesity/overweight, Mediterranean diet, nutritional adequacy, Portugal, Portuguese population, pregnancy, and prenatal programming.

Assessment of study quality included the number of study participants, the instruments used to assess dietary intake and adherence to a Mediterranean-like diet, the accuracy of overweight/obesity assessment, and the adjustment for potential confounders.

\section{Selected studies}

Five good quality multinational ecological studies that have included Portugal data and assessed the diet of women of childbearing age and pregnant women ${ }^{3,15-18}$ were analyzed.

Two national official surveys on food availability including women of childbearing age, ${ }^{19,20}$ seven national studies on the diet and nutritional status of women of childbearing age and pregnant women ${ }^{21-27}$ and five national studies on the effect of maternal factors on their growing fetuses ${ }^{28-32}$ were analyzed.

\section{RESULTS}

\section{Food availability in Portugal as a European country}

The selling price of food became the lowest in many European countries. ${ }^{33}$ However, this economic advantage has not always been accompanied by the improvement in quality. Agriculture policies in European Union in particular have encouraged the low cost production of sugar, fats, oils, and meat through subsidies and other measures, compared with the limited market supply of fruits and vegetables. ${ }^{33}$ Food industry has developed several food products, rich in fat, sugar, and consequently, in energy. These food products fit well with the consumers' desire regarding flavor, convenience, and price. The rising availability of these energy-dense foods is likely a major driver of the obesity epidemics. $^{33}$

The household food security was surveyed in Portuguese population in 2013, through a survey carried out by the Portuguese Directorate-General of Health Ministry, using an United States Department of Agriculture adapted scale in adults attending health care centers; financial insufficiency was reported by 351 responders, with a prevalence of 
$25.4 \%(95 \% \mathrm{Cl} ; 23.1-27.7)$, as the main reason for not always acquiring foods that they wanted or needed..$^{19}$ Another survey assessing the Portuguese household spending trend carried out by the Statistics Portugal in 2010 - 2011 found that in 1989 - 1990 the Portuguese families allocated $29.5 \%$ of their budget for food and non-alcoholic beverages, whereas in 2010 - 2011 this proportion has decreased to $13.3 \% .^{20}$

\section{Diet transition in Portugal as a Mediterranean country}

Mediterranean countries traditionally have been characterized by their high consumption of plant foods, fresh and seasonal fruits, beans, nuts, fish, and olive oil; however, this traditional pattern has diminished accordingly with increase in overweight and non-communicable diseases. . $^{3,33}$

The modernized environment provides foods characterized by high energy per unit weight due to extra fat and/or sugars along with energy-rich drinks, leading to ample opportunity for the consumption of very energydense diets. ${ }^{33}$

In a review addressing the consumption of industrially produced trans fatty acids in 24 countries around the world between 2004 - 2007, Portugal was approximately at a median position, with consumption of $20 \mathrm{~g}-30 \mathrm{~g}$ of a 'high trans fat menu' consisting of fast food, biscuits/ cakes/wafers, and microwave popcorn. ${ }^{15}$ The high consumption of this dietary fat results from the relatively cheap hydrogenation of vegetable oils utilized for industrial hardening to increase product stability for handling and storage. ${ }^{15}$ High dietary intakes of trans fatty acids have been associated with increased risk of weight gain and gain in abdominal fatness. ${ }^{34}$ Additionally, trans fatty acids have been related with deceleration in fetal growth velocity, an issue addressed below. ${ }^{28}$

Recent ecological studies have assessed the nutritional transition over roughly 40 years in European and nonEuropean countries of different geographical areas, including changes in adherence to the Mediterranean-like dietary pattern. ${ }^{3,16-18}$ Based on the Food and Agriculture Organization food balance sheets, these studies concluded that a majority of countries have tended to drift away from a Mediterranean-like dietary pattern, with the Mediterranean European countries, including Portugal, experiencing the greatest decrease in Mediterranean diet adherence. . $^{3,16,17}$ Among these studies, Mediterranean Adequacy Index was used by da Silva et $a l^{17}$ to assess in 41 countries the changes in Mediterranean diet adherence from the years 1961 - 1965 to 2000 - 2003. Vareiro et $a^{\beta}$ evaluated in five geographical areas the changes in the availability of the most important food components of the traditional Mediterranean diet and other food groups from the years 1961 - 1965 to 2000 - 2004, and found that the greatest changes occurred in Mediterranean Europe, recording high availability of non-Mediterranean food groups (animal fats, vegetable oils, sugar and meat), whereas the availability of vegetables decreased. This is line with the aforementioned low cost production of these non-Mediterranean food groups compared with limited market supply of fruits and vegetables in European Union. ${ }^{33}$ Balanza et a/ ${ }^{16}$ analyzed food patterns changes in Mediterranean Europe from the years 1961 - 1963 to 1998 - 2000, and concluded that the greatest changes were characterized by $20.1 \%$ increase in total energy intake, $48.1 \%$ increase in energy availability from lipids, and $20.5 \%$ decrease in energy available from carbohydrates, associated with $29.9 \%$ decrease in energy supplied by cereals and $77.8 \%$ increase in the contribution of milk and $23.6 \%$ in dairy products to total energy intake.

\section{Diet and nutrition status in women of childbearing age and pregnant women in Portugal}

Few national studies have assessed dietary intake of Portuguese women of childbearing age and pregnant women throughout the last decades (Table 1).

The most representative epidemiological studies about dietary intake during pregnancy in Portugal are based on the Geração XXI, the largest Portuguese birth cohort. This cohort enrolled 8,654 infants born to women who delivered in 2005 - 2006 in the maternity clinics of the five public hospitals in Porto, representing $91.6 \%$ of the deliveries in the whole catchment population. ${ }^{23}$

In a subsample of 101 pregnant women of Geração XXI cohort, a single administration of a semi-quantitative food frequency questionnaire (FFQ) in the immediate postpartum period has been validated for Portuguese pregnant women in comparison with a 3-day food diary in nonconsecutive days in each trimester as reference method. ${ }^{21}$ In a further study nested within the Geração XXI cohort, selfreported intakes were compared with concentrations of fatty acids in adipose tissue in 23 pregnant women biopsied at $37-39$ weeks of gestation. The correlations found between self-reported intakes and tissue concentrations were weaker than those observed in a similar study including non-pregnant women. This suggests that adipose tissue levels of fatty acids is a poor biomarker of dietary intake in late pregnancy, presumably because tissue levels are likely to reflect the balance between maternal intake and fetal use. ${ }^{22}$

In another study recruiting a subsample of 249 pregnant women of Geração XXI cohort followed-up from early gestation (before 13 gestational weeks), ${ }^{23}$ the maternal diet and nutritional adequacy prior to conception and during pregnancy was assessed using the validated FFQ. ${ }^{21}$ It was observed that the reported energy and macronutrients intakes were within recommended levels for most women. ${ }^{23}$ Prior and during pregnancy, the micronutrients with higher inadequacy prevalences were respectively $83 \%$ and $73 \%$ for vitamin E, $58 \%$ and $91 \%$ for folate, and $19 \%$ and $21 \%$ for magnesium; during pregnancy, inadequacy prevalence of $88 \%$ for iron was also found, which was higher among women who were overweight prior to pregnancy (OR $=3.45 ; 95 \% \mathrm{Cl} ; 1.22-9.71, p=0.01)$; the self-reported prevalences of supplementation of iron and magnesium increased throughout pregnancy; $97 \%$ of women reported 
that folic acid supplementation has initiated at median gestational age of 6.5 (interquartile range 5.9) weeks. ${ }^{23}$ Complying with the study design, women with a gestational age above 13 weeks at entry and those whose pregnancies ended in miscarriages, stillbirths and very preterm births were excluded; as diet has been shown to be associated with adverse pregnancy outcomes, these exclusions may have affected the estimates of reported food and nutrient intakes, being a weakness of the study. ${ }^{23}$

Maternal nutrition adequacy during pregnancy was assessed in a cohort of 94 singleton pregnant women aged at least 18-years without chronic or acute diseases, undergoing parental preparation at a first care unit and followed-up to 34 weeks of gestation. The impact of one nutritional education session during pregnancy on the diet was also assessed. ${ }^{24}$ Using the FFQ validated for Portuguese pregnant women, ${ }^{21}$ excessive consumption of total fat $(47.9 \%)$ and sodium $(47.9 \%)$, and inadequacies of iron $(93.6 \%)$, folate $(88.3 \%)$, vitamin D (100\%), vitamin $E$ (85.1\%), n-3 fatty acids (50.0\%), n-6 fatty acids $(79.9 \%)$, and fiber $(59.6 \%)$ were identified, ${ }^{24}$ in the subsample of women who attended the nutritional education session, higher adequate prevalences of carbohydrates, fat, fiber, $n-3$ and n- 6 fatty acids, iron, folate, vitamin $D$, and vitamin $E$ were observed, ${ }^{24} 56.4 \%$ of pregnant women who attended the nutritional education session reported changing their diet according to the healthy advised habits; those not complying with mentioned recommendations had higher gestational weight gain (GWG) ${ }^{24}$ A limitation in this study was the lost of information from participants who have attended the nutritional education session but did not complete the questionnaire. ${ }^{24}$

A recent study carried out in 2010 - 2012 assessed predictors of adherence to Mediterranean diet from the first to the second trimesters of pregnancy in 102 Portuguese women included in the Geração XXI cohort. ${ }^{25}$ Food consumption was assessed using a 3-day food diary completed during the first and second trimesters. Change in adherence to the Mediterranean diet was categorized into the negative defined as low adherence in each trimester or higher adherence in the first trimester, or the positive defined as high adherence in both trimesters or lower

Table 1 - Studies on diet and nutrition status of Portuguese pregnant women

\begin{tabular}{|c|c|}
\hline Citation & Aim, study design and sample size \\
\hline $\begin{array}{l}\text { Pinto E, et al } \\
(2010)^{21}\end{array}$ & $\begin{array}{l}\text { Aim: validation of a single administration of a semi- } \\
\text { quantitative food frequency questionnaire in the } \\
\text { immediate post-partum period. } \\
2004-2005 \text { : cohort, longitudinal survey. } \\
(n=101)\end{array}$ \\
\hline $\begin{array}{l}\text { Pinto E, et al } \\
(2010)^{22}\end{array}$ & $\begin{array}{l}\text { Aim: assessment of adipose tissue levels of fatty acids } \\
\text { as biomarker of dietary intake in pregnancy. } \\
2004-2005 \text { : cross-sectional invasive study, single } \\
\text { center. } \\
(n=23)\end{array}$ \\
\hline
\end{tabular}

Pinto E, et al. Aim: assessment of diet prior to conception and during $(2009)^{23} \quad$ pregnancy.

2005 - 2006: cohort, longitudinal survey.

$(n=249)$

Domingos I Aim: assessment of maternal nutrient adequacy during $(2012)^{24} \quad$ pregnancy, and the impact of one nutritional education session on the diet during pregnancy. 2011: cross-sectional survey, single center. $(n=70)$

Abreu S, et al Aim: assessment of predictors of adherence to $(2015)^{25} \quad$ Mediterranean diet from the first to the second trimesters of pregnancy.

2010 - 2012: cross-sectional survey, single center. $(\mathrm{n}=102)$

do Carmo, et al Aim: assessment of obesity based on anthropometric $(2008)^{26}$

\section{Results}

The tested food frequency questionnaire is a reproducible and valid tool to rank Portuguese women according to their dietary intake, in comparison with a 3-day food diary in non-consecutive days in each trimester (reference method).

The correlations between self-reported intakes and tissue concentrations were weaker than those observed in a similar study including non-pregnant women, suggesting that adipose tissue levels of fatty acids are a poor biomarker of dietary intake in late pregnancy.

Reported energy and macronutrient intakes were within recommended levels for most women.

Prior and during pregnancy, higher inadequacy prevalences were found for vitamin $\mathrm{E}$, folate, and magnesium; during pregnancy, higher inadequacy prevalence for iron was also found during pregnancy.

Excessive consumption of total fat and sodium, and insufficient consumption of iron, folate, vitamins $D$ and $\mathrm{E}, \mathrm{n}-3$ and $\mathrm{n}-6$ fatty acids, and fiber were identified. Women who attended one nutritional education session had higher adequate prevalences for most of the aforementioned micronutrients, while those who did not comply with recommendations had higher gestational weight gain.

$39.2 \%$ of women revealed a negative change of adherence to Mediterranean diet from the first to the second trimester, less negative among married women and those consuming more vegetables in the first trimester.

High prevalence of overweight/ obesity was found in women of childbearing age, directly proportional to their age: $18-19$ years $20.8 \%, 20-29$ years $27.3 \%$ and 30 39 years $50.1 \%$. 2003 - 2005: nationwide survey on obesity,
subsample of women aged 18 - 39 years. $(n=2,617)$ 
adherence in the first trimester. ${ }^{25}$ It was found that $39.2 \%$ of participants had a negative change from the first to the second trimester; after adjustment for potential confounding factors, being married $(\mathrm{OR}=0.26 ; 95 \% \mathrm{Cl} ; 0.10-0.76)$ and having higher vegetables intake in the first trimester $(\mathrm{OR}=0.17 ; 95 \% \mathrm{Cl} ; 0.10-0.43)$ were associated with a lower occurrence of negative change in adherence to the Mediterranean diet from early to middle pregnancy. ${ }^{25}$ The relatively low number of participants for identifying small effects, potential differences of this sample in relation to the population for which the index was originally designed, and non-controlled predictors potentially associated with the outcome are limitations of this study. ${ }^{25}$

A Portuguese nationwide representative survey assessing obesity, based on anthropometric measurements undertaken in the years 2003 - 2005, enrolled 8,116 participants aged $18-64$ years. ${ }^{26}$ Increased overweight/ obesity prevalence of $53.6 \%$ was found comparing to the $49.6 \%$ in the 1995 - 1998 survey based on similar data collecting methodology. ${ }^{26}$ High overweight/obesity prevalences were found in the subsample of 2,617 women aged 18 - 39 years (of childbearing age), which were directly proportional to their ages: 18 - 19 years $20.8 \%, 20$ 29 years $27.3 \%$ and $30-39$ years $50.1 \%{ }^{26}$

A cross-sectional study enrolled a consecutive sample of 88 pregnant women from the Geração XXI cohort, attending a primary health care unit, in order to assess the impact of pre-pregnancy overweight/obesity, GWG, and other factors on hypertensive disorders (chronic hypertension, gestational hypertension or pre-eclampsia/ eclampsia) during pregnancy. ${ }^{27}$ Overall, hypertensive disorders affected $4.6 \%$ of single pregnancies and $37.5 \%$ women were overweight/obese at the last visit before pregnancy; the GWG was greater than recommended in $50 \%$ and $30.8 \%$ of women who were overweight or obese before pregnancy, respectively. Excessive weight before and during pregnancy had a very large contribution for hypertensive disorders during pregnancy, with joint effect of older age, family history of cardiovascular disease, and lower education. ${ }^{27}$ The small number of participants and the self-reported pre-pregnancy body mass index (BMI) are limitations of this study.

\section{Nutrition status in Portuguese women: impact on their growing fetus}

During pregnancy, the fetus receives all required nutrients through maternal-fetal blood circulation and is dependent on maternal nutrient stores and dietary intake. In scenarios of severe dietary restriction, such as during the Dutch famine, the impact of maternal diet on fetal growth is undeniable. ${ }^{35}$ However, in the context of normal food availability, the effect of maternal diet on fetal growth

Table 2 - Studies on the impact of nutrition status of Portuguese pregnant women on their offspring

\begin{tabular}{ll}
\hline Citation & Aim, study design and sample size \\
\hline Pinto E, et al & Aim: assessment of the effect of maternal diet on fetal \\
$(2009)^{28}$ & growth trajectories. \\
& $\begin{array}{l}\text { 2008: cohort study } \\
(\mathrm{n}=218 \text { mother-infant pairs })\end{array}$
\end{tabular}

Leventakou V, Aim: assessment of the effect of fish intake during et al (2014) ${ }^{18} \quad$ pregnancy on fetal growth and length of gestation.

2011: population-based study of 19 European birth cohorts, including Portugal.

$(n=359)$

Pinto E, et al Aim: assessment of associations of cord and maternal $(2010)^{29} \quad$ insulin-like growth factors levels with birth size and cord lipids.

2009: cross-sectional study

( $n=196$ mother-infant pairs)

Pereira-da- Aim: assessment of the adjusted effect of pre-pregnancy Silva L, et al body mass index, energy and macronutrient intakes $(2014)^{30} \quad$ during pregnancy and gestational weight gain on offspring body composition.

2010 - 2011: cross-sectional study

( $\mathrm{n}=100$ mother-infant pairs)

Pereira-daSilva L, et al $(2015)^{31}$
Aim: assessment of the adjusted effect of LCPUFA intake during pregnancy on adiposity early after birth. 2010 - 2011: cross-sectional study ( $\mathrm{n}=100$ mother-infant pairs)

\section{Results}

Maternal total energy, protein and carbohydrate intakes had no effect on fetal growth, with exception of deceleration in fetal growth in the last half of pregnancy associated with highest intakes of total fat, saturated fat, trans and n-6 fatty acids.

Moderate fish intake was associated with slightly longer gestational age and moderately higher birth weight.

A relatively high fish intake was found in Portuguese pregnant women.

Birth size was more strongly associated with cord than with maternal IGF-1 levels.

Cord IGF-1 levels were positively associated with cord lipid high-density lipoprotein cholesterol levels and negatively with cord triglyceride levels.

Positive associations were found between:

- both pre-pregnancy body mass index and energy intake from carbohydrate and offspring body size in the whole sample

- pre-pregnancy overweight and adiposity in male offspring

- gestational weight gain and body size in female offspring

Positive associations were found between:

- maternal docosahexaenoic acid intake and birth size in male offspring

- $n-6: n-3$ LCPUFA ratio intake and adiposity in female offspring 
is much more complex to determine, namely because of several determinants of fetal growth and a plausible interaction between them (i.e., maternal nutritional status and maternal diet). ${ }^{36}$

In epidemiological studies, newborn size at birth has been frequently used as a proxy of fetal growth. However, it is possible that different growth trajectories end in the same size at birth, with different means in terms of fetal programming. ${ }^{37}$

Few studies have assessed the influence of maternal nutritional factors of Portuguese pregnant women on their growing fetuses (Table 2).

The effect of maternal diet on fetal growth trajectories was assessed in 218 singleton pregnant women from the Geração XXI cohort, whose diets were ascertained by a semi-quantitative FFQ. ${ }^{28}$ Fetal weight was estimated based on ultrasound measures taken after the $17^{\text {th }}$ gestational week, using mixed linear regression models with random effects in the interception to predict growth trajectories. Maternal total energy, protein, and carbohydrate intakes had no effect on fetal growth, but highest intakes of total fat, saturated fat, trans and n- 6 fatty acids were found to be associated with deceleration in fetal growth during the last half of pregnancy. ${ }^{28}$

A large multinational study on 19 European birth cohort studies, including the Portuguese Geração XXI cohort, assessed the effect of fish intake during pregnancy on the fetal growth and length of gestation. ${ }^{18}$ Individual data from cohorts were pooled and harmonized and adjusted cohortspecific effect estimates were combined by using a random and fixed-effects meta-analysis. ${ }^{18}$ Portuguese women were among the more frequent fish consumers in Europe, with a median intake of 4.5 times/wk (interquartile range 3.5), compared with the overall median intake of 0.5 times/wk. ${ }^{18}$ Consumption of fish $>3$ times/wk during pregnancy was associated with a slightly longer gestational age by 0.2 days (95\% Cl; 0.1 - 0.4 days) and moderately higher birth weight by $15.2 \mathrm{~g}(95 \% \mathrm{Cl} ; 8.9-21.5 \mathrm{~g})$ than women who rarely ate fish ( $\leq 1$ time/wk). ${ }^{18}$ It may be speculated that this benefit is related to the geographical advantage of the Portugal's wide Atlantic coast.

Beyond environmental factors, including nutrient supply, fetal growth is regulated by genetic and endocrine factors. The main endocrine determinants of fetal growth are insulin and insulin-like growth factors (IGFs). ${ }^{38}$ The production of these hormones is regulated by the glucose concentration; therefore, decrease in glucose concentration leads to a lower production of insulin and IGFs and, consequently, restriction of fetal growth. ${ }^{38}$ Their production is also affected by fat intake in adults, and animal studies suggest that the same type of regulation can occur during intrauterine growth. ${ }^{39}$ In this context, associations between cord and maternal IGFs levels and both birth size and cord lipids were examined in a subsample of 196 mother-infant pairs from the Geração XXI cohort. ${ }^{29}$ Birth size was more strongly associated with cord than with maternal IGF-1 levels; specifically, for each standard deviation increment in log IGF-1 cord levels, birth weight increased by $371 \mathrm{~g} \mathrm{(95 \%} \mathrm{Cl;} 287$ - $456 \mathrm{~g})$. Cord IGF-1 levels were also positively associated with cord lipid high-density lipoprotein cholesterol levels and negatively associated with cord triglyceride levels. ${ }^{29}$

A cross-sectional study on 100 Portuguese motherinfant pairs was carried out in 2010 - 2011 in a public maternity, to evaluate the adjusted effect of three major maternal factors on offspring's body composition: prepregnancy $\mathrm{BMI}$, energy and macronutrient intakes during pregnancy, and GWG ${ }^{30}$ A FFQ validated for Portuguese pregnant women ${ }^{21}$ was used. Only full-term appropriate-forgestational age neonates born after apparently uneventful gestations have been enrolled. Their body composition was assessed early after birth using anthropometry and air displacement plethysmography. Positive associations were found between both pre-pregnancy BMI and energy intake from carbohydrate and offspring body size in the whole sample; between pre-pregnancy overweight and adiposity in male offspring; and between GWG and body size in female offspring. ${ }^{30}$ In a systematic review and metaanalysis of 30 prospective studies, significant and strong independent associations with childhood overweight were identified for maternal pre-pregnancy overweight, high infant birth weight, and rapid weight gain during the first year of life..$^{40}$

A systematic review and meta-analysis including 20 studies assessed the association between maternal pre-pregnancy BMI and/or GWG and offspring body composition in childhood. ${ }^{41}$ Standardized mean differences in body fat percent, fat mass, and fat-free mass between infants of women with normal pre-pregnancy BMI and those of overweight/obese women were 0.31 percent points (95\% Cl; $0.19-0.42), 0.38 \mathrm{~kg}(95 \% \mathrm{Cl} ; 0.26-0.50)$, and $0.18 \mathrm{~kg}(95 \% \mathrm{Cl} ;-0.07-0.42)$, respectively. These results suggest that pre-pregnancy overweight is associated with higher offspring adiposity. ${ }^{41}$ The mechanisms underlying maternal programming of offspring adiposity are still unclear One potential explanation may be a proinflammatory intrauterine environment promoted by maternal obesity, the resulting lipotoxicity can alter fetal development pathways via dysregulation of redox balance in the mother-placentafetus unit, which serves as one of the key downstream mediators that initiate programming of the offspring. ${ }^{42,43}$ The mechanisms responsible for the reported sexual dimorphism in offspring adiposity as consequence of maternal overnutrition are unknown. In experimental models, strong maternal programming of adiposity in male offspring but not in female offspring was described. ${ }^{44,45}$ In humans, fat mass of mother have been associated either to male, ${ }^{30,46}$ or to female offspring adiposity. ${ }^{47}$

Nested within the same aforementioned cross-sectional study on 100 mother-infant pairs, the adjusted effect of longchain polyunsaturated fatty acid (LCPUFA) intake during pregnancy on the adiposity of offspring was also evaluated early after birth. ${ }^{31}$ Positive associations were found between maternal docosahexaenoic acid intake and birth size in male offspring $(\beta=0.165 ; 95 \% \mathrm{Cl} ; 0.031-0.299, p=0.017)$, 
and between $n-6: n-3$ LCPUFA ratio intake and adiposity in female offspring $(\beta=0.636 ; 95 \% \mathrm{Cl} ; 0.125-1.147$, $p=0.016) \cdot{ }^{31}$ The association between offspring adiposity and maternal LCPUFA ratio intake favoring $n-6$ over $n-3$ LCPUFA is in coherence with the reported adipogenic effect of $n-6$ fatty acids family and anti-adipogenic effect of $n-3$ fatty acids family. ${ }^{48}$

A cross-sectional community-based survey of Portuguese children, assessed the association between GWG and offspring's overweight in childhood. ${ }^{32}$ Among the enrolled 4,845 children aged $8.5 \pm 0.91$ years, the prevalence of overweight/obesity was $29 \%$ in boys and $33 \%$ in girls. ${ }^{32}$ The odds favoring overweight/obesity increased significantly for those women who recalled GWG ${ }^{3} 16 \mathrm{~kg}$, compared to those with GWG $<9 \mathrm{~kg}$, even after adjustment for confounders (adjusted OR = 1.27; Cl 95\%; 1.01 - 1.61, $p$-trend $=0.038$ ). This suggests that high GWG may be a latter sign of prenatal programming of adipogenesis. ${ }^{32,46}$ A systematic review of 23 cohort studies examined the independent association of GWG with overweight status in offspring aged two to 18.9 years and suggested that GWG is a potential risk factor for childhood obesity. ${ }^{49}$ In a recent cohort study enrolling 977 mother-infant pairs, different effects related to timing of excessive GWG were found..$^{50}$ Greater GWG rate (per $200 \mathrm{~g} / \mathrm{wk}$ ) in the first trimester of pregnancy was associated with increased risk of overweight/ obesity from two years [RR 1.25; 95\% Cl; 1.09 - 1.42] to four years (RR $1.15 ; 95 \% \mathrm{Cl} ; 1.05-1.25)$ of age but not with birth size, while greater GWG rate during the last trimesters was associated with greater risk of large-for-gestationalage neonates (RR 1.22; 95\% Cl; 1.02 - 1.45) but not with child anthropometry at later ages. ${ }^{50}$

\section{Limitations in dietary assessment}

Limitations regarding dietary assessment in some of the analyzed studies need to be acknowledged.

Food balance sheets only allow assessment of food availability, that is, the total amount of food available for consumption by all country residents in a period of time, and not exactly what people eat. ${ }^{51}$ Despite this instrument's inability to provide insight into subpopulations, it is expected that the aforementioned changes in Mediterranean Europe, including Portugal, have also occurred in women of childbearing age and pregnant women.

Similarly to other indexes, the Mediterranean diet scores have limitations, including the variability in defining cut-off points for the scoring components, and the lack of agreement over the definition of the Mediterranean diet. ${ }^{52,53}$ Nevertheless, the indices used to assess adherence to the
Mediterranean diet have shown satisfactory performance, but further studies are required to select the components, the number of components, and the scoring criteria of the indexes to improve their internal consistency, in order to improve the reliability and concordance between the indices. ${ }^{52}$

\section{CONCLUSION}

Similar to the most of Mediterranean Europe, abandonment of the Mediterranean diet-like pattern by Portuguese population has occurred in the last decades. Factors potentially contributing to low adherence to the Mediterranean diet, deserving further investigation, are European Union agriculture policies that have implemented the production of non-Mediterranean food groups at low cost, and the insufficient financial capacity to afford foods of quality reported by Portuguese population.

Associated with the trend of low adherence to Mediterranean diet, the prevalence of overweight/obesity has dramatically increased in Portugal, including in women of childbearing age and pregnant women.

The nutrition factors present in Portuguese pregnant women with potential impact on their growing fetuses is mostly similar to that described in other countries and populations. In recent cohort studies, it was found that energy and macronutrient intakes by Portuguese pregnant women seem to be within recommended levels, and with few exceptions their variations do not seem to affect the nutritional status of the growing fetus. On contrary, pre-pregnancy overweight/obesity is associated with increased offspring adiposity at birth, and excessive GWG is associated with offspring's overweight in childhood. Therefore, preventing or treating weight excess in women of childbearing age should be a priority.

\section{ACKNOWLEDGMENTS}

The authors are grateful to Kayla M. Bridges, MS, RD, CSP, CNSC, St. John Providence Children's Hospital, Detroit, MI, USA and Department of Nutritional Sciences, School of Health Related Professions, Rutgers, The State University of New Jersey, Newark, NJ, USA, for the critical review of the manuscript.

\section{CONFLICTS OF INTEREST}

The authors declare that there are no conflicts of interest.

\section{FUNDING SOURCES}

No subsidies or grants contributed to this work.

\section{REFERENCES}

1. Schröder $\mathrm{H}$. Protective mechanisms of the Mediterranean diet in obesity and type 2 diabetes. J Nutr Biochem. 2007;18:149-60.

2. Bach-Faig A, Berry EM, Lairon D, Reguant J, Trichopoulou A, Dernini S, et al. Mediterranean diet pyramid today. Science and cultural updates. Public Health Nutr. 2011;14:2274-84.

3. Vareiro D, Bach-Faig A, Raidó Quintana B, Bertomeu I, Buckland G, Vaz de Almeida MD, et al. Availability of Mediterranean and non-
Mediterranean foods during the last four decades: comparison of several geographical areas. Public Health Nutr. 2009;12:1667-75.

4. Kontogianni MD, Vidra N, Farmaki A-E, Koinaki S, Belogianni K, Sofrona S, et al. Adherence rates to the Mediterranean diet are low in a representative sample of Greek children and adolescents. J Nutr. 2008;138:1951-6.

5. Aounallah-Skhiri H, Traissac P, Ati J El, Eymard-Duvernay S, Landais 
$\mathrm{E}$, Achour $\mathrm{N}$, et al. Nutrition transition among adolescents of a southMediterranean country: dietary patterns, association with socioeconomic factors, overweight and blood pressure. A cross-sectional study in Tunisia. Nutr J. 2011;10:38.

6. Grosso G, Marventano S, Buscemi S, Scuderi A, Matalone M, Platania $A$, et al. Factors associated with adherence to the Mediterranean diet among adolescents living in Sicily, southern Italy. Nutrients. 2013;5:4908-23.

7. Naska A, Trichopoulou A. Back to the future: the Mediterranean diet paradigm. Nutr Metab Cardiovasc Dis. 2014;24:216-9.

8. Nurmatov $U$, Devereux $G$, Sheikh A. Nutrients and foods for the primary prevention of asthma and allergy: Systematic review and meta-analysis. J Allergy Clin Immunol. 2011;127:724-33.

9. Grosso G, Mistretta A, Marventano S, Purrello A, Vitaglione P, Calabrese $G$, et al. Beneficial effects of the Mediterranean diet on metabolic syndrome. Curr Pharm Des. 2014;20:5039-44.

10. Timmermans S, Steegers-Theunissen RP, Vujkovic M, den Breeijen $\mathrm{H}$, Russcher $\mathrm{H}$, Lindemans $\mathrm{J}$, et al. The Mediterranean diet and fetal size parameters: the Generation R Study. Br J Nutr. 2012;108:1399-409.

11. Chatzi L, Mendez M, Garcia R, Roumeliotaki T, Ibarluzea J,Tardón A, et al. Mediterranean diet adherence during pregnancy and fetal growth: INMA (Spain) and RHEA (Greece) mother-child cohort studies. Br J Nutr. 2012;107:135-45.

12. Steenweg-de Graaff J, Tiemeier $H$, Steegers-Theunissen RPM, Hofman A, Jaddoe VW, Verhulst FC, et al. Maternal dietary patterns during pregnancy and child internalising and externalising problems. The Generation R Study. Clin. Nutr. 2014;33:115-21.

13. Spencer SJ. Early life programming of obesity: the impact of the perinatal environment on the development of obesity and metabolic dysfunction in the offspring. Curr Diabetes Rev. 2012;8:55-68.

14. Georgoulis M, Kontogianni MD, Yiannakouris N. Mediterranean diet and diabetes: Prevention and treatment. Nutrients. 2014;6:1406-23.

15. Astrup A, Dyerberg J, Selleck M, Stender S. Nutrition transition and its relationship to the development of obesity and related chronic diseases. Obes Rev. 2008;9:48-52.

16. Balanza R, García-Lorda P, Pérez-Rodrigo C, Aranceta J, Bonet MB Salas-Salvadó J. Trends in food availability determined by the Food and Agriculture Organization's food balance sheets in Mediterranean Europe in comparison with other European areas. Public Health Nutr. 2007;10:168-76

17. Silva R da, Bach-Faig A, Raidó Quintana B, Buckland G, Vaz de Almeida MD, Serra-Majem L. Worldwide variation of adherence to the Mediterranean diet, in 1961-1965 and 2000-2003. Public Health Nutr 2009;12:1676-84.

18. Leventakou V, Roumeliotaki T, Martinez D, Barros $H$, Brantsaeter $A L$, Casas $M$, et al. Fish intake during pregnancy, fetal growth, and gestational length in 19 European birth cohort studies. Am J Clin Nutr. 2014;99:506-16.

19. Direcção Geral da Saúde. Programa Nacional para a Promoção da Alimentação Saudável. Portugal - Alimentação Saudável em números - 2014. [Accessed: 2015 Dec 26]. Available at: https://www.dgs.pt/ estatisticas-de-saude/estatisticas-de-saude/publicacoes/portugalalimentacao-saudavel-em-numeros-2014.aspx.

20. Intituto Nacional de Estatística. Inquérito às despesas das famílias 2010/2011. 2012. [Accessed: 2015 Dec 26]. Available at: file://C:/Users/ Luis/Downloads/IDEF 20102011 b\%20(2).pdf

21. Pinto E, Severo M, Correia S, dos Santos Silva I, Lopes C, Barros $\mathrm{H}$. Validity and reproducibility of a semi-quantitative food frequency questionnaire for use among Portuguese pregnant women. Matern Child Nutr. 2010;6:105-19.

22. Pinto E, Ramos E, Severo M, Casal S, dos Santos Silva I, Lopes C, et al. Measurement of dietary intake of fatty acids in pregnant women: comparison of self-reported intakes with adipose tissue levels. Ann Epidemiol. 2010;20:599-603.

23. Pinto $\mathrm{E}$, Barros $\mathrm{H}$, dos Santos Silva I. Dietary intake and nutritional adequacy prior to conception and during pregnancy: a follow-up study in the north of Portugal. Public Health Nutr. 2009;12:922-31.

24. Domingos I. Avaliação da adequação nutricional e do impacto duma intervenção de educação nutricional numa coorte de grávidas portuguesas. Acta Obstet Ginecol Port. 2012;6:19-28.

25. Abreu S, Santos PC, Moreira P, Santos R, Moreira C, Montenegro N, et al. Predictors of adherence to the Mediterranean diet from the first to the second trimester of pregnancy. Nutr. Hosp. 2014;31:1403-12.

26. do Carmo I, Dos Santos O, Camolas J, Vieira J, Carreira M, Medina L, et al. Overweight and obesity in Portugal: national prevalence in 20032005. Obes Rev. 2008:9:11-19.
27. Alves $E$, Azevedo A, Rodrigues $T$, Santos AC, Barros H. Impact of risk factors on hypertensive disorders in pregnancy, in primiparae and multiparae. Ann Hum Biol. 2013;40:377-84.

28. Pinto E, Severo M, Cunha A, De Stavola B, Santos Silva I, Barros H. Maternal diet throughout pregnancy and foetal growth trajectories. Eur $\mathrm{J}$ Epidemiol. 2009;24:90.

29. Pinto E, Ramos E, Guimarães JT, Santos Silva I, Barros H. Maternal blood IGFs, cord blood IGFs and lipids, and size at birth: implications for adult dislypidemia. Epidemiol Prev. 2010;34(suppl 1).

30. Pereira-da-Silva L, Cabo C, Moreira AC, Virella D, Guerra T, Silva AR, et al. The adjusted effect of maternal body mass index, energy and macronutrient intakes during pregnancy, and gestational weight gain on body composition of full-term neonates. Am J Perinatol. 2014;31:87582.

31. Pereira-da-Silva L, Cabo C, Moreira AC, Papoila AL, Virella D, Guerra T, et al. The effect of long-chain polyunsaturated fatty acids intake during pregnancy on adiposity of healthy full-term offspring at birth. J Perinatol. 2015;35:177-80.

32. Moreira P, Padez C, Mourão-Carvalhal I, Rosado V. Maternal weight gain during pregnancy and overweight in Portuguese children. Int $J$ Obes. 2007;31:608-14.

33. Branca F, Nikogosian $H$, Lobstein $T$. The challenge of obesity in the WHO European Region and the strategies for response. WHO Report. Geneve: WHO; 2007.

34. Koh-Banerjee P, Chu NF, Spiegelman D, Rosner B, Colditz G, Willett W, et al. Prospective study of the association of changes in dietary intake, physical activity, alcohol consumption, and smoking with 9-y gain in waist circumference among 16587 US men. Am J Clin Nutr. 2003;78:719-27.

35. Stein AD, Zybert PA, van de Bor M, Lumey LH. Intrauterine famine exposure and body proportions at birth: the Dutch Hunger Winter. Int $J$ Epidemiol. 2004;33:831-6.

36. Moore VM, Davies DM. Diet during pregnancy, neonatal outcomes and later health. Reprod Fertil Dev. 2005;17:341-8.

37. Harding JE. The nutritional basis of the fetal origins of adult disease. Int J Epidemiol. 2001;30:15-23.

38. Fowden AL, Forhead AJ. Endocrine regulation of feto-placental growth. Horm Res. 2009;72:257-65.

39. Heald AH, Sharma R, Anderson SG, Vyas A, Siddals K, Patel J, et al. Dietary intake and the insulin-like growth factor system: effects of migration in two related populations in India with markedly different dietary intake. Public Heal Nutr. 2005;8:620-7.

40. Weng SF, Redsell SA, Swift JA, Yang M, Glazebrook CP. Systematic review and meta-analyses of risk factors for childhood overweight identifiable during infancy. Arch Dis Child. 2012;97:1019-26.

41. Castillo-Laura H, Santos IS, Quadros LC, Matijasevich A. Maternal obesity and offspring body composition by indirect methods: a systematic review and meta-analysis. Cad Saude Publica. 2015;31:2073-92.

42. Saben J, Zhong Y, Gomez-Acevedo H, Thakali KM, Borengasser SJ, Andres A, et al. Early growth response protein-1 mediates lipotoxicityassociated placental inflammation: role in maternal obesity. AJP Endocrinol Metab. 2013;305:E1-14.

43. Malti N, Merzouk H, Merzouk SA, Loukidi B, Karaouzene N, Malti A, et al. Oxidative stress and maternal obesity: Feto-placental unit interaction Placenta. 2014:35:411-6.

44. Ainge H, Thompson C, Ozanne SE, Rooney KB. A systematic review on animal models of maternal high fat feeding and offspring glycaemic control. Int J Obes. 2011;35:325-35.

45. Alfaradhi MZ, Ozanne SE. Developmental programming in response to maternal overnutrition. Front Genet. 2011;2:1-13.

46. Andres A, Hull HR, Shankar K, Casey PH, Cleves MA, Badger TM. Longitudinal body composition of children born to mothers with normal weight, overweight, and obesity. Obesity. 2015;23:1252-8.

47. Henriksson $P$, Löf $M$, Forsum E. Parental fat-free mass is related to the fat-free mass of infants and maternal fat mass is related to the fat mass of infant girls. Acta Paediatr. 2015;104:491-7.

48. Hauner $\mathrm{H}$, Brunner $\mathrm{S}$, Amann-gassner $\mathrm{U}$. The role of dietary fatty acids for early human adipose tissue growth. Am J Clin Nutr. 2013;98:549-55.

49. Lau EY, Liu J, Archer E, McDonald SM, Liu J. Maternal weight gain in pregnancy and risk of obesity among offspring: a systematic review. J Obes. 2014:2014:1-16.

50. Karachaliou M, Georgiou V, Roumeliotaki T, Chalkiadaki G, Daraki V, Koinaki S, et al. Association of trimester-specific gestational weight gain with fetal growth, offspring obesity, and cardiometabolic traits in early childhood. Am J Obs Gynecol. 2015;212:502.e1-14.

51. Gibson RS. Food consumption at the national and household levels. In: Principles of Nutritional Assessment. New York: Oxford University 
Press; 2005.

52. Milà-Villarroel R, Bach-Faig A, Puig J, Puchal A, Farran A, Serra-Majem $L$, et al. Comparison and evaluation of the reliability of indexes of adherence to the Mediterranean diet. Public Health Nutr. 2011;14:2338-

\section{5.}

53. Bach A, Serra-Majem L, Carrasco JL, Roman B, Ngo J, Bertomeu I, et al. The use of indexes evaluating the adherence to the Mediterranean diet in epidemiological studies: a review. Public Health Nutr. 2006;9:132-46. 